ings in close proximity to them, the fact is of considerable physiological importance and Parker's work in this connexion is of great interest. But co-ordination by a blood-circulated hormone has different physiological attributes from nervous co-ordination; and it is therefore a purely verbal compromise between issues which are not factually consistent to claim that in the light of the neurohumoral hypothesis the distinction of a nervous and humoral excitation really vanishes "because both rely for their effective. ness on liberated substances which from a near or far source reach and excite a given colour cell".

The book is attractively produced on paper of unusually high quality. It is certain to remain the standard work on the subject for several years.

H. WARING

\section{NUMERICAL METHODS}

The Differential Analyser

By J. Crank. Pp. viii $+137+4$ plates. (London, New York and Toronto : Longmans, Green and Co., Ltd., 1947.) 10s. $6 d$. net.

\section{Computing Mechanisms and Linkages}

By Antonín Svoboda. Edited by Hubert M. James. (Massachusetts Institute of Technology : Radiation Laboratory Series, No. 27.) Pp. xii+359. (New York and London: MeGraw-Hill Book Co., Inc., 1948.) $27 s$. HE growing importance of numerical methods
in scientific research is reflected in the beginnings
of a separate literature. These two books are con-
cerned not with methods, but with tools, and are
welcome additions to the small number of books
dealing with this field. They are both concerned with
what have been called analogue machines, and not
with the digital type of calculator which is now
exciting a good deal of attention. Although they are
both concerned with analogue devices, the scope of
the two books is very different. Mr. Crank describes
the differential analyser, which is used for the solution
of differential equations, and is purposely designed
to cover a wide variety of problems, and Prof. Svoboda
is concerned with the design of simple mechanisms
to represent specific functions.

Mr. Crank's little book is adequate without being heavy, and not unreasonably expensive. The author worked on the differential analyser at the University of Manchester, and later took charge of the very similar machine at Cambridge. He speaks with the authority of working experience of this equipment, and the description both of the machine and methods of its use is simple and clear. The needs of the research worker who wishes to understand and use the differential analyser have been fully met, so far as they can be without practical demonstration on the machine itself; and the author goes a long way to help the isolated worker, without access to an existing machine or to experienced guidance, who wishes to design a machine of moderate accuracy and cost for himself. The amount of useful knowledge packed into this small book is quite remarkable.

Two minor points of criticism, which are rather matters of personal preference, might be noted for a future edition. The long list of references at the end of Chapter 6 on 'applications' would be more conven. ient if arranged in alphabetical order of the authors ; and in his deseription of the new differential analyser at the Massachusetts Institute of Technology, the author would have done well to include a reference to Prof. S. H. Caldwell's D.Se. thesis; in this thesis there are also some interesting remarks on method which should not be forgotten.

Prof. Svoboda's book is No. 27 of the Massachusetts Institute of Technology's Radiation Laboratory Series, and is, in fact, an essay in the neglected subject of kinematics devoted to a severely practical need. Prof. Svoboda is concerned with bar linkage mechanisms and their use for the approximate generation of functions required in connexion with fire control, in particular gun predictors. He shows that with two basic mechanisms, the harmonic transformer and the three-bar linkage, it is possible to perform the fundamental operations of arithmetic, addition, subtraction, multiplication and division, and to generate ballistic functions. The interesting point that arises in this book is that although the field of functions which can be generated exactly by a combination of these two mechanisms is limited, if one is satisfied with an approximate description and works to definite tolerances, a wide variety of functions can be generated within these limits of accuracy. Prof. Svoboda describes a definite design method. He shows how a crude approximation may be refined in successive stages until the desired degree of accuracy is reached.

The theory of these mechanisms is fully developed in the book, and excellent charts and tables are given for those who wish to use its methods. The book also has the virtue of being complete in itself. Although well written and clearly expressed, it might be difficult reading for the engineer. Nevertheless, the reviewer is convinced that the theory here developed will have useful engineering applications apart from the war-time applications described.

JOHN WOMERSLEY

\section{WILD ANIMALS AND THE LAND}

\section{Wild Animals and the Land}

By F. Howard Lancum. Pp. $136+29$ plates. (London: Crosby Lockwood and Son, Ltd., 1947.) 10s. $6 d$. net.

MR. HOWARD LANCUM in this book writes I primarily for men of the land who wish to know something of the status of British wild animals in relation to agriculture, horticulture and food production, and has produced an attractive book, illustrated by excellent photographs. Some of the animals he describes are the fox, the badger, the otter, rabbit and hare, the hedgehog and squirrel, rat, vole, mice and shrew. It is good to see that he mentions the good, as well as the harm, animals do. For example (p. 32), we are told of the fondness of the badger for wasps' grubs. When a wasps' nest had to be tackled, "it was a common occurrence for a deputation of youngsters to present itself at the door of the house of Brocky's [the tame badger's] master, with the request, 'Can we borrow Brocky, please?' Brocky was ever ready to be borrowed, for none knew better than he what was afoot. He would be duly led away with collar and chain until the company came within sight of the offending wasps' nest. As soon as he saw the flying wasps his hackles would rise, and he was released from the chain while the children remained at a safe distance. In an almost incredibly short time Brocky would have that nest 